\title{
Advances in low-protein diets for swine
}

Yuming Wang ${ }^{1,2}$, Junyan Zhou ${ }^{1,2}$, Gang Wang ${ }^{1,2}$, Shuang Cai ${ }^{1,2}$, Xiangfang Zeng ${ }^{1,2}$ and Shiyan Qiao ${ }^{1,2^{*}}$

\begin{abstract}
Recent years have witnessed the great advantages of reducing dietary crude protein (CP) with free amino acids (AA) supplementation for sustainable swine industry, including saving protein ingredients, reducing nitrogen excretion, feed costs and the risk of gut disorders without impairing growth performance compared to traditional diets. However, a tendency toward increased fatness is a matter of concern when pigs are fed low-protein (LP) diets. In response, the use of the net energy system and balanced AA for formulation of LP diets has been proposed as a solution. Moreover, the extent to which dietary CP can be reduced is complicated. Meanwhile, the requirements for the first five limiting AA (lysine, threonine, sulfur-containing AA, tryptophan, and valine) that growing-finishing pigs fed LP diets were higher than pigs fed traditional diets, because the need for nitrogen for endogenous synthesis of non-essential AA to support protein synthesis may be increased when dietary CP is lowered. Overall, to address these concerns and give a better understanding of this nutritional strategy, this paper reviews recent advances in the study of LP diets for swine and provides some insights into future research directions.
\end{abstract}

Keywords: Amino acid, Crude protein, Growth performance, Gut health, Net energy, Nutrient balance, Pig

\section{Background}

In pig production, the dietary crude protein $(\mathrm{CP})$ content can be reduced when the requirements for essential amino acids (EAA) and total nitrogen are met, because for pigs the need for dietary protein is essentially a need for amino acids (AA) [1]. Because of limited lysine content in corn, higher amount of soybean meal (SBM) was included in traditional corn-soybean meal (CSBM) diets to meet lysine requirement of pigs, which resulted in high CP levels [2]. High-protein (HP) diets led to excesses of other EAA and excretion of excess nitrogen in feces and urine, resulting in lowering the efficiency of nitrogen utilization. Additionally, protein fermentation in hindgut can damage the gut health. Reducing the dietary CP by $2 \%$ to $4 \%$ from the NRC (1998) [3] recommendations and supplementing with crystalline amino acids (CAA) has been demonstrated to increase nitrogen utilization, reduce feed costs and nitrogen excretion, and promote gut health without impairing the growth

\footnotetext{
*Correspondence: qiaoshy@nferc.org

'State Key Laboratory of Animal Nutrition, College of Animal Science and

Technology, China Agricultural University, Beijing 100193, China

${ }^{2}$ Beijing Key Laboratory of Biological Feed Additive, China Agricultural

University, Beijing 100193, China
}

performance of pigs [4-7]. Low-protein (LP) diets in these studies supplemented with four crystalline amino acids (FCAA) ( $L$-lysine, $D L$-methionine, $L$-threonine and $L$-tryptophan) because they are the first four limited AA needed to be added to balance for an ideal protein ratio.

The latest NRC (2012) [8] for standard nutrient requirements of swine eliminated the recommendations for $\mathrm{CP}$ requirement and replaced it with a total nitrogen requirement. If the total nitrogen requirement of NRC (2012) [8] is multiplied by the common CP coefficient of 6.25 , the $\mathrm{CP}$ requirement is $2 \%$ to $4 \%$ lower than the recommended value of the NRC (1998) [3]. This indicated that the study of LP diets had advanced and the advancement could be applied to pig production. With the development of industrial synthetic AA technology, supplementary feedgrade AA, such as $L$-valine and $L$-isoleucine have become available for use in livestock diets, resulting in the potential for further reduction in dietary CP.

One of the most variables of concern when pigs are fed LP diets is the fatter carcass compared with HP diets $[9,10]$, which may be partially due to more dietary energy being available for fat deposition in LP diets [4]. The adoption of the net energy (NE) system when formulating LP diets for pigs has been suggested by several 
authors in the last few years as means to still achieve acceptable performance, carcass characteristic and meat quality $[4,11,12]$.

To give a better understanding of LP diets and provide a reference for further study, this paper reviews the advantages of LP diets in reducing feed costs and nitrogen excretion, and promoting gut health. The influence on growth performance and the application of the NE system in LP diets have also been highlighted. Finally, a summary of the published recommendations for dietary standardized ileal digestible (SID) EAA and NE in LP diets are provided.

\section{The advantages of LP diets}

\section{Saving protein ingredients and reducing feed costs of pigs}

The shortage of high quality protein sources is a worldwide problem, especially in China. Globally, China is the largest soybean importer since 2002 [13]. In 2016, China's soybean imports were 8,391 million tons and accounted for more than $26 \%$ of the worldwide production; therefore, reducing the dietary protein content could effectively reduce pressure on protein ingredient supplies. Summarizing recent studies evaluating LP diets fed to pigs, we can conclude that every $10 \mathrm{~g} / \mathrm{kg}$ reduction of dietary CP resulted in a $3 \%$ reduction in protein ingredient inclusion (Fig. 1). Interestingly, the energy source is increased by almost $3 \%$, equal to the reduction in protein source of every $10 \mathrm{~g} / \mathrm{kg}$ reduction of dietary CP (Fig. 2). Thus, the application of LP diets can also be considered a cost-effective alternative feeding strategy due to higher price of protein ingredients versus energy sources. The SBM is the most widely fed protein source in pig diets, with a high and consistent product quality, has more than doubled over the last 7 years due to less acreage used to grow soybeans [14]. For instance, the

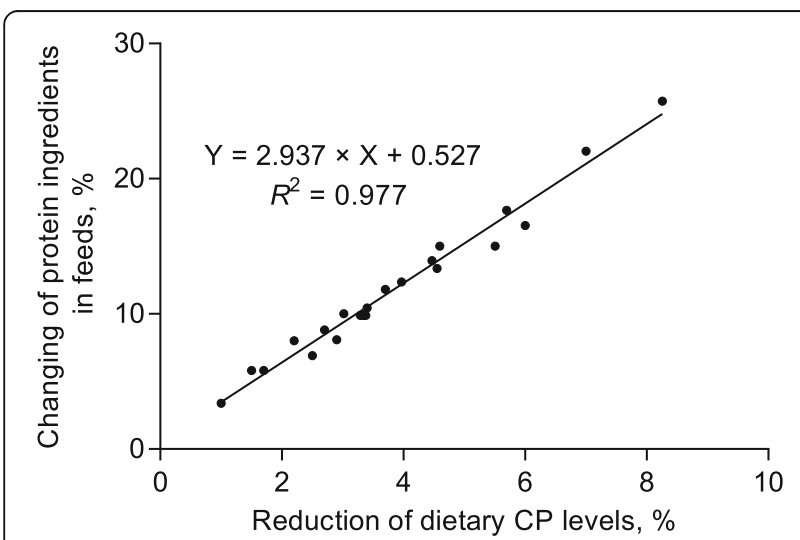

Fig. 1 Linear relationship between the reduced percentage of dietary protein ingredients and CP reduction levels for pigs. The data of regression analysis summarized from 10 published research articles evaluating the effect of LP diet on pig performance $[1,5,19,38,77,130-134]$

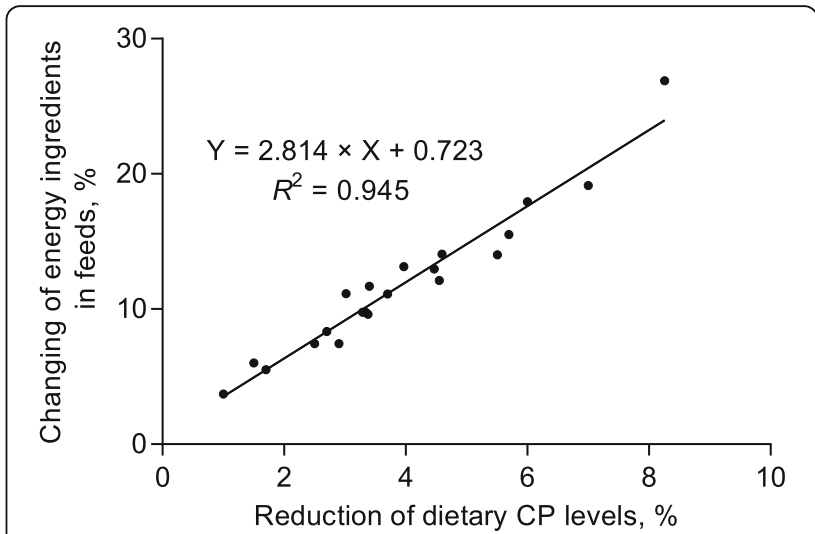

Fig. 2 Linear relationship between the increased percentage of dietary energy ingredients and CP reduction levels for pigs. The data of regression analysis summarized from 10 published research articles evaluating the effect of $L P$ diet on pig performance $[1,5,19,38,77,130-134]$

price ratio of SBM to energy feeds (corn and wheat are the most widely feed energy sources) is more than $150 \%$ in China. Other protein ingredients like cottonseed meal, rapeseed meal and distillers dried grains with soluble (DDGS) are also more expensive than energy feeds [15]. Therefore, considering less protein ingredient inclusion and greater energy source inclusion and the cost of additional supplemented CAA in LP diets, every $10 \mathrm{~g} / \mathrm{kg}$ of reduction of $\mathrm{CP}$ could decrease feed cost by about $1.50 \%$ in China [16]. The exact savings of LP diets to pig production are influenced by other factors, including the fluctuations in the market price of feedstuffs and CAA, feed cost per kilogram of BW gain and the value of products obtained for a given performance, and the reduced cost of environmental protection.

\section{Nitrogen emission}

Nitrogen excretion is the major criticism in modern pig production because of the negative impact on the environment, such as manure ammonia $\left(\mathrm{NH}_{3}\right)$ contribution to acidification and eutrophication of sensitive ecosystems and odor emissions [17]. The concentration of $\mathrm{CP}$ in traditional CSBM diets is elevated in order to satisfy the requirement of lysine because lysine is the first limiting AA in CSBM based diets. Consequently, the overabundance of other AA is broken down into nitrogen and the excess nitrogen excreted in the urine as urea. One effective approach to decreasing the nitrogen emission is to reduce the content of dietary $\mathrm{CP}$, supplementing with CAA, to come close to matching the pig's ideal protein pattern. Based on an assumed ideal protein pattern, the LP diets improved the utilization efficiency of nitrogen without affecting the digestibility and retention of nitrogen [10]. Most studies indicated that a reduction of dietary $\mathrm{CP}$ more than $20 \mathrm{~g} / \mathrm{kg}$ could effectively 
decrease the nitrogen emission. The effect of dietary $\mathrm{CP}$ reduced levels on nitrogen excretion of pigs are represented in Fig. 3. Every $10 \mathrm{~g} / \mathrm{kg}$ reduction of dietary CP can decrease ammonia emission from feces and urine by $8 \%$ to $10 \%$. In addition, lower dietary $\mathrm{CP}$ level resulted in reduced water intake, along with decreased urea nitrogen excretion in urine $[5,18]$. Serum or plasma urea nitrogen (SUN or PUN), the main and ultimate nitrogenous product of protein catabolism, has also been detected at lower concentrations in pigs fed with LP diets compared with the normal protein diets [19]. Therefore, these two factors can be used as easily determinable indicators of reduced nitrogen excretion [20].

Odor emissions from pig production units can be a nuisance in the surrounding area. Often the production of odorants is a consequence of anaerobic fermentation of undigested proteins in animal manure [17]. In this respect, the reduction of dietary $\mathrm{CP}$ could decrease odor emissions. Hayes et al. [21] found odor emission rates were significantly reduced by $31 \%$ and $33 \%$ for the 160 and $130 \mathrm{~g} / \mathrm{kg} \mathrm{CP}$ diets in comparison to the $190 \mathrm{~g} / \mathrm{kg}$ $\mathrm{CP}$ diet, and odor emission from pigs fed $190 \mathrm{~g} / \mathrm{kg} \mathrm{CP}$ diet was similar to the CP level of $220 \mathrm{~g} / \mathrm{kg}$. Alternatively, Leek et al. [22] studied a similar range of dietary CP levels $(130,160,190$ and $210 \mathrm{~g} / \mathrm{kg}$ ) and reported that the odor emission rate was lowest at $160 \mathrm{~g} / \mathrm{kg} \mathrm{CP}$ but increased as the $\mathrm{CP}$ concentration was reduced to $130 \mathrm{~g} / \mathrm{kg}$. This contradictory response in odor emission may be related to a higher level of sulfur-containing AA (supplemented crystalline $D L$-methionine) in $130 \mathrm{~g} / \mathrm{kg}$ CP diets because the fermentation products of sulfur-containing AA including $\mathrm{H}_{2} \mathrm{~S}$, dimethylsulphide, dimethyldisulphide and dimethyltrisulphide have been correlated with odor concentration [23].

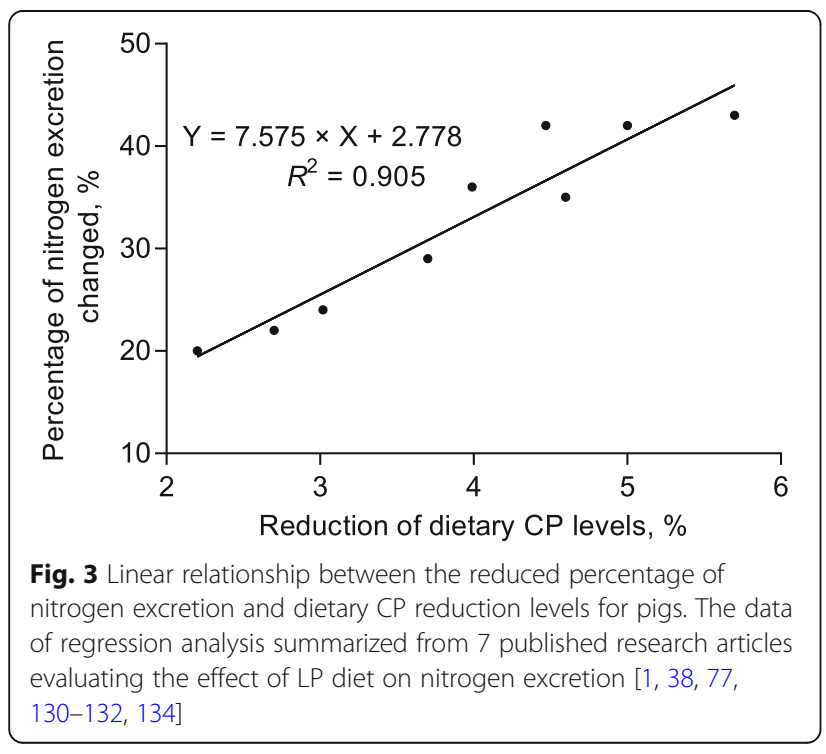

\section{Gut health}

Many studies have reported that LP diets effectively lowered the incidence of post-weaning diarrhea (PWD), maintain gut health, and had distinct influence on intestinal morphology and microbiota.

\section{Lowering incidence of post-weaning diarrhea of piglets}

In weaning period, the feed is transited from liquid (milk) to solid, accompanied with changes of psychological, environment, morphological and microbial in the gastro-intestinal tract (GIT) of young pigs [24]. These changes are often associated with a high incidence of PWD in this period. In-feed antibiotics have been extensively used as an effective preventative measures for PWD [25]; however, the appearance of antimicrobial resistance (AMR) caused a global concern about the negative effects of sub-therapeutic use of antibiotics. As a result, a ban on the use of in-feed antibiotics was introduced in 2006 in the Europe, and the World Health Organization (WHO) released its Global Action Plan on AMR in 2015. Accordingly, alternative nutritional strategies to control the PWD are useful options and also will not cause security concern, such as reducing dietary $\mathrm{CP}$ of weanling piglets.

The fermentation of undigested protein and AA by the intestinal microbiota are important factors contributing to PWD [26]. Numerous metabolites are produced from protein fermentation in the hindgut, such as short- or branched-chain fatty acids (SCFAs, BCFAs) [27], sulfur-containing bacterial metabolites (methanethiol, $\mathrm{H}_{2} \mathrm{~S}$ ), aromatic compounds (phenolic, indolic compounds), polyamines, and ammonia [28]. Some of the metabolites are beneficial to the host; for example, SCFAs may be used as an energy source by the host or regulate cell proliferation and differentiation and BCFAs have been shown to regulate electrolyte absorption and secretion $[29,30]$. However, the relative proportions of fatty acids that come from protein fermentation are present at much lower concentrations and their production is mainly regulated by available concentrations of carbohydrates [31]. The ammonia, polyamine, phenol and indole products of fermentation represent potential toxins to host health, such as cytopathic effects on epithelia cells, or inhibiting mitochondrial oxygen as metabolic troublemakers towards colonocyte energy metabolism [32]. Moreover, HP diets have higher acid-binding capacity and increase $\mathrm{pH}$ of the GIT to nearly neutral conditions, which provide a favorable environment for the proliferation of pathogenic bacteria, such as Bacteroides and Clostridium species, thereby increasing PWD incidence [33]. Thus, reducing the amount of protein reaching the large intestine by selecting highly digestible protein ingredients or lowering the dietary protein level may help to alleviate PWD. 
Although a full description of protein sources is beyond the scope of this article, animal protein exhibits a superior feeding value than plant protein partly due to higher digestibility [34]; therefore fishmeal and whey powder often used in young pig diets.

The CP level of typical CSBM diets for weaned piglets in the nursery phase (i.e. from 7 to $20 \mathrm{~kg}$ body weight) commonly varies from $21 \%$ to $25 \%$ according to the hygiene situation of pig farms or production goals [35]. Many studies have investigated the extent of dietary CP reduction needed to effectively lower PWD. Yue and Qiao [6] reduced the dietary CP level from $23.1 \%$ to $18.9 \%$ of supplementing with FCAA and reported lower PWD and a simultaneous improvement in fecal consistency. A further reduction to $17.2 \%$ decreased growth performance despite addition of $L$-isoleucine, $L$-valine, $L$-histidine, and $L$-phenylalanine to achieve an ideal AA pattern. Therefore, it was suggested that reduced dietary CP for piglets should be no more than 4 percentage units below NRC (1998) [3] or 2 percentage units below NRC (2012) [8] recommendations because other non-essential amino acids (NEAA) may become limiting with further reduction resulting in poor performance $[1,5]$. However, a study of long-term feeding of LP diets for weanling piglets indicated that a reduction of $\mathrm{CP}$ levels from $24.3 \%$ to $17.3 \%$ supplemented with EAA to conform to an ideal AA pattern can reduce the PUN and $\mathrm{NH}_{3}-\mathrm{N}$, resulting in lower PWD of weanling piglets over the whole period without compromising production [36]. Similar results were reported in a subsequent study using pigs infected with an enterotoxigenic strain of Escherichia coli (E. coli) [37]. Many other studies also showed a similar trend in the incidence of PWD when feeding LP diets (not less than $17 \%$ ) to weanling piglets $[38,39]$.

\section{Intestinal morphology}

Evidence suggests that LP diets have no significant influence on the intestinal and mucosal weight [40]. Pigs fed LP diets exhibited decreased crypt depth in sections of the small intestine and a tendency for greater villus height to crypt depth ratio, which implied that LP diets could effectively improve the digestion and absorption of the small intestine [41]. Deeper crypts and notable villus atrophy were observed $3 \mathrm{~d}$ after enterotoxigenic E. coli (ETEC) challenge in the ileum of weaned piglets fed a $22.5 \%$ CP diet compared with those fed a $17.6 \% \mathrm{CP}$ diet [42]. This result further confirmed that LP diets could alleviate alterations in intestinal morphology induced by pathogenic bacteria and maintain the normal digestion and absorption capacity of intestinal cells. However, further reduction by more than $4 \%$ resulted in a significant reduction in villous height in both duodenum and jejunum even though diets were supplemented with $L$-isoleucine, $L$-valine, $L$-histidine and $L$-phenylalanine [6,7]. The reduction of villous height in pigs fed LP diets are likely related to less protein to maintain the architecture of intestinal epithelium. In general, reducing the dietary $\mathrm{CP}$ level within a suitable range not more than 3 percentage units will not modify the intestinal morphology integrity [40].

\section{Intestinal microbiota}

The mammalian intestine is colonized with many thousands of microbiota strains with the total number of microbial cells exceeding $10^{14}$ [43]. Intestinal microbiota play an important role in host physiology and metabolism [44]. Undigested dietary protein fermentation is possibly associated with an enhanced proliferation of protein-fermenting bacteria [45]. Therefore, the source, quality and level of dietary protein may have an influence on microbial communities. Many studies reported that dietary $\mathrm{CP}$ level rather than its source has more significant impacts on the composition of the intestinal microbiota [24]. The influence of dietary CP levels on the intestinal microbiota communities has been more widely studied in weaned piglets, because the structure of bacterial composition of growing or finishing pigs remains relatively stable. In a study with newly weaned piglets, reduced dietary $\mathrm{CP}$ decreased counts of Clostridium leptum, but had no effect on total bacteria, Lactobacilli, Enterobacteria and Bacteroides [46]. A culture-independent method using denaturing gradient gel electrophoresis (DGGE) indicated that the numbers of Firmicutes and Clostridium cluster IV were lower in pigs fed $14 \%$ dietary CP than in $20 \%$ dietary CP with minimal impact on other bacteria populations [47]. Principally, it seemed that the dietary CP level influences the Clostridium genus. Opapeju et al. [42] reported that in young pigs challenged with ETEC, reducing dietary $\mathrm{CP}$ can significantly lower the amount of ETEC in both ileum and colon. However, many other studies reported that changes in dietary $\mathrm{CP}$ content had no significant influence on the bacterial communities in all sections of the intestine under normal physiological conditions, because the microbiota can adapt to a certain extent following changes in dietary CP level [48]. Results of studies evaluating the effect of dietary CP level on the composition of microbiota are inconsistent. However, many of these studies were performed using the traditional culture-dependent or low throughput culture-independent methods and these methods are limited to detection of bacteria that can be cultured in vitro or are abundant in vivo.

With the application of high-throughput sequencing, $16 \mathrm{~S}$ rRNA gene sequencing has been widely used in biological studies and may help in developing a comprehensive understanding of the influence of dietary CP level on variation in intestinal bacteria. In a long-term feeding experiment $(100 \mathrm{~d})$, pyrosequencing of the $\mathrm{V} 1-\mathrm{V} 3$ region 
of the $16 \mathrm{~S}$ rRNA gene showed a 3\% reduction in dietary $\mathrm{CP}$ decreased the relative abundance of Lactobacillus in the cecum and Streptococcus in the colon of growing pigs compared with a HP diet [49]. Moreover, the ileum and colon microbiota of finishing pigs were also influenced by dietary $\mathrm{CP}$ levels, where a moderate reduction of dietary CP concentration (no more than 3\%) improved the bacterial community structure in both the ileum and colon of finishing pigs; specifically increases in the proportion of Peptostreptococcaceae which are helpful in maintaining gut homeostasis [7].

Conventional wisdom suggested that adult mammals have a stable intestinal microbiota population that is difficult to influence by dietary strategies in comparison to weaned piglets harboring unstable microbiota populations [50]. Additionally, previous studies focused on the changes of hindgut microbiota and neglected the effect of bacteria in the small intestine [51]. With the application of high-throughput sequencing, the microbial communities of different physiological stages and gut locations have provided evidence that the intestinal microbiota population may be changed by different dietary $\mathrm{CP}$ contents.

\section{Immune response}

Soybean contains many anti-nutritional factors including trypsin inhibitor, agglutinins, antigenic proteins, isoflavones and alkaloids which impede the digestion and absorption of nutrients [52]. Furthermore, undigested antigen proteins in soybeans can enter the lymph and blood through the gaps between intestinal epithelial cells and stimulate hypersensitivity for weanling piglets [53]. Therefore, lowering the CP level as a nutritional strategy to decrease the soybean content of diets could be in part, ameliorate immune stress of piglets at weaning [54].

Growing evidence has demonstrated that supplementing LP diets with free AA can have various biological effects besides use for protein synthesis. For example, dietary supplementation with CAA modulates gene expression, reduces excessive body fat, enhances growth of intestine and skeletal muscle and contributes to immunologic defense and minimizing gut disorder [55-57]. Particularly under stress conditions, supplementing with CAA in LP diets can modify immune status and improve the resistance to subclinical and clinical diseases [58].

Threonine A sufficient intake of dietary threonine is particularly important for mucosal mucin synthesis and maintaining integrity of the gut barrier [59]. Wang et al. [57] reported that an increase in true ileal digestible (TID) threonine from $0.37 \%$ to $0.89 \%$ with $16 \%$ CP in weanling pigs can significantly improve the concentrations of ileal acidomucins, duodenal sulfomucins and the total amounts of mucins in the duodenum. However, a further increase to $1.11 \%$ resulted in downregulation of intestinal mucin expression and derangement of the intestinal mucosal epithelial barrier. Serum IgG concentrations also increased in response to increased intake of TID threonine where $0.85 \%$ threonine intake was the optimum level [59]. In addition, the threonine required to maximize the immune response is greater than for maximum weight gain and increased threonine levels in LP diet increased plasma antibody concentration [60].

Sulfur amino acids Sulfur amino acids (SAA) are important for the immune system; methionine provides the methyl group for the synthesis of spermidine and spermine which is important for the proliferation and differentiation of lymphocytes [61]. Cysteine is the precursor of glutathione (GSH), homocysteine (Hcy) and taurine which play crucial roles in the response to immunological challenges. A deficiency of cysteine suppresses epithelial growth, impairs the proliferation of lymphocytes, reduces the production of CD4 cells and IFN $\gamma$, and diminishes T-cell activity [62]. Under immune system stimulation, additional SAA intake had an obligation to maintain whole body protein synthesis due to increased immune protein synthesis [63].

Tryptophan Tryptophan plays a role in immune responses via products of its catabolism, such as serotonin, melatonin and $\mathrm{N}$-acetylserotonin which can inhibit the production of superoxide and TNF $\alpha$, eliminate free radicals, and modulate inducible nitric oxide $(\mathrm{NO})$ synthesis [56]. Additionally, available evidence indicates that tryptophan catabolism may produce a local immunosuppressive effect to control T-cell homeostasis during inflammation [64]. Trevisi et al. [65] reported that supplementation of $0.1 \% L$-tryptophan to a standard weaning $\operatorname{diet}(\mathrm{CP} 19 \%$, analyzed tryptophan: lysine $=0.20$ ) allowed piglets with a greater susceptibility to ETEC K88 and maintain an adequate body growth rate. In growing pigs fed LP diets, dietary SID tryptophan to lysine ratio of at least $22 \%$ maximized production potential and increased resistance to inflammation and immune response under commercial conditions [66]. Similar results were reported in a recent study from the weaning to finishing phase conducted under different sanitary conditions [58].

Branched-chain amino acids Branched-chain amino acids (BCAA) provide the carbon skeletons for endogenous synthesis of glutamine, which is an abundant AA in plasma, skeletal muscle, fetal fluids and milk and is a major energy substrate for immune cells [67]. The BCAA can also be used as the precursors for the synthesis of new immune cells, effector molecules, and protective molecules [68]. A recent study reported that a protein restricted diet (CP 17\%, analyzed leucine, valine, 
and isoleucine to lysine ratio was $0.87,0.51$, and 0.41 , respectively) supplemented with BCAA (0.07\% L-leucine, $0.27 \% L$-valine, and $0.19 \% L$-isoleucine) could improve intestinal immune defense functions by protecting villous morphology and increasing intestinal immunoglobulins levels in weaned piglets [69].

Lysine and arginine In general, a lysine deficiency would not directly affect the host immune response, but would limit the synthesis of proteins (including cytokines) and the proliferation of lymphocytes [70]. Further, because lysine shares the same transport systems with arginine, the content of dietary available lysine can modulate the metabolism of arginine [71]. Arginine is a nutritionally EAA for piglets due to insufficient endogenous synthesis and it has been reported that dietary arginine supplementation could enhance immune response of weaned pigs [72]. N-carbamylglutamate (NCG) has been demonstrated to increase endogenous synthesis of arginine by activating intestinal pyrroline-5-carboxylate synthase and carbamylphosphate synthase-1 [73]. It is widely used as a feed additive instead of $L$-arginine- $\mathrm{HCl}$ because of concerns over the short biological half-life of arginine and the arginine/lysine antagonism [74]. Recent studies have demonstrated that NCG supplementation has some beneficial effects on intestinal mucosal immunity associated with stimulated lymphocyte proliferation and cytokine synthesis [75].

\section{Inclusion of fermentable carbohydrates in LP diets}

Recently, the inclusion of moderately fermentable carbohydrates seems to be the most promising approach to maximize the efficacy of LP diets and has been presented in considerable detail by other reviews $[17,24,76]$ and won't be discussed in detail here. However, from these reviews we can conclude that the inclusion of fermentable carbohydrates into the LP diet may provide the following advantages in pig production: 1) divert nitrogen excretion from urine to feces; 2) increase SCFAs production while reducing the slurry $\mathrm{pH}$; 3) the carbohydrates would be preferential substrates for microbial fermentation over protein. Combined with the reduction in excretion of nitrogen, emission of $\mathrm{NH}_{3}$, incidence of diarrhea and production of odorants would also be reduced; all of which are beneficial to piglet growth and the environment.

\section{Influence of dietary CP level on pig production performance}

Low-protein diets have the advantage of reducing feed cost and nitrogen excretion, and amelioration of the diarrhea rate of weaning piglets. However, pig production performance should not be compromised when feeding with LP diets. Therefore, the influence of dietary $\mathrm{CP}$ level on growth performance, carcass characteristic and meat quality are included as an important criterion to justify LP diets.

\section{Growth performance}

Growth performance, including ADG, ADFI and F:G is the first factor to evaluate LP diets and also an indicator that is relatively simple to determine. It is well accepted that dietary CP reduction within 3\% of the NRC (1998) [3] and supplemented with FCAA can result in similar growth performance in growing-finishing pigs as those of the control diets [77].

However, conflicting results are reported on the influence of a further reduction in dietary $\mathrm{CP}$ level on growth performance by more than 3\% (Table 1). Retarded growth performance was reported when the CP level was reduced by more than $3 \%$ with only FCAA supplemented in diets [6]. Roux et al. [78] reported that a reduction of CP by $4.8 \%$ along with FCAA supplementation resulted in significantly decreased growth performance compared with pigs fed HP diets. Whereas, the reduced performance was alleviated with valine and isoleucine supplementation implying that BCAA may be the next-limiting AA in LP diets. Similar results were reported by Powell et al. [79]. Supplementing BCAA to LP diets can increase growth performance by increasing the feed intake and skeletal muscle growth in piglets [80]. Zhang et al. [19] also showed that dietary BCAA content was the limiting factor affecting the growth performance of fattening pigs with $4.5 \%$ reduction in dietary $\mathrm{CP}$ content.

Further reduction is more than 6\% CP level would be possible when supplemented with all EAA without affecting pig growth performance, which implies that NEAA does not seem to be limited in very low-protein (VLP) diets for growing pigs [81]. However, Guay et al. [40] reported poor performance in growing pigs fed diets with $8.3 \% \mathrm{CP}$ reduction even though all the EAA were added to a same level as the control group (16.1\% dietary $\mathrm{CP}$ ). This suggests that insufficient NEAA or total nitrogen may be the reason for the poor growth performance [82]. In addition, some AA that are typically considered as NEAA may become essential when the dietary CP is below a certain level in the LP diet [83]. The conditionally EAA arginine and cysteine would likely be the first-limiting AA and dependent on de novo synthesis to optimize growth in VLP diets while the EAA were satisfied [79]. Nevertheless, Gloaguen et al. [1] showed that young pigs fed a 12.7\% $\mathrm{CP}$ diet, supplemented with sufficient amount of EAA and NEAA, had reduced growth performance compared with pigs fed a $19.7 \% \mathrm{CP}$ diet. The poor performance in pigs fed VLP diet may be due to a deficiency in intact protein or excess of free AA. Inclusion of 
Table 1 The variation in performance of pigs fed diets with CP reduced by more than $3 \%$

\begin{tabular}{|c|c|c|c|c|c|c|c|}
\hline \multirow[t]{2}{*}{ BW, kg } & \multicolumn{2}{|c|}{ Dietary CP level ${ }^{a}, \%$} & \multirow[t]{2}{*}{ Additional supplemented $\mathrm{AA}^{\mathrm{b}}$} & \multicolumn{3}{|c|}{ Performance changed ${ }^{c}$} & \multirow[t]{2}{*}{ References } \\
\hline & Control diet & LP diet & & $\mathrm{ADG}, \mathrm{g} / \mathrm{d}$ & $\mathrm{ADFl}, \mathrm{kg} / \mathrm{d}$ & $\mathrm{F}: \mathrm{G}, \mathrm{kg} / \mathrm{kg}$ & \\
\hline \multirow[t]{3}{*}{$24 \sim 40$} & 24.1 & 19.3 & Valine & -38 & -0.24 & -0.12 & Morales et al. [81] \\
\hline & & 18.1 & Valine, leucine, isoleucine, histidine, phenylalanine & -33 & -0.06 & -0.01 & \\
\hline & & 17.3 & Valine, leucine, isoleucine, histidine, phenylalanine, glycine & -13 & -0.04 & -0.03 & \\
\hline \multirow[t]{2}{*}{ 7 11} & 23.1 & 18.9 & - & $14^{d}$ & 0.02 & -0.01 & Yue and Qiao [6] \\
\hline & & 17.2 & Valine, isoleucine, histidine, phenylalanine & $57^{d}$ & 0.50 & $-0.14^{d}$ & \\
\hline $6 \sim 13$ & 22.8 & 17.4 & Isoleucine & $121^{d}$ & $0.11^{d}$ & $-0.30^{\mathrm{d}}$ & Nyachoti et al. [5] \\
\hline $50 \sim 80$ & 19.5 & 12.0 & Valine, leucine, isoleucine, histidine & $111^{d}$ & 0.07 & $0.25^{d}$ & Atakora et al. [135] \\
\hline $10 \sim 20$ & 19.4 & 12.7 & Valine, histidine, isoleucine, leucine, phenylalanine & $70^{\mathrm{a}}$ & -0.01 & $-0.35^{d}$ & Gloaguen et al. [1] \\
\hline \multirow[t]{5}{*}{$20 \sim 50$} & 18.2 & 13.3 & - & $44^{d}$ & 0.03 & -0.09 & Powell et al. [79] \\
\hline & & 13.4 & Valine, isoleucine & 27 & -0.02 & -0.12 & \\
\hline & & ! & Glycine, arginine & $64^{d}$ & 0.08 & -0.10 & \\
\hline & & ! & Valine, isoleucine, glycine, arginine & 13 & 0.04 & 0.02 & \\
\hline & & $!$ & Valine, isoleucine, glycine, glutamic acid & 8 & 0.03 & 0.02 & \\
\hline \multirow[t]{2}{*}{$20 \sim 45$} & 18.2 & 13.3 & - & $56^{d}$ & -0.01 & $-0.26^{d}$ & Roux et al. [78] \\
\hline & & 13.4 & Valine, isoleucine & 30 & $-0.12^{\mathrm{d}}$ & $-0.26^{\mathrm{d}}$ & \\
\hline \multirow[t]{2}{*}{$37 \sim 61$} & 16.1 & 10.1 & Valine, isoleucine, phenylalanine & $171^{d}$ & 0.01 & $-0.44^{d}$ & Guay et al. [40] \\
\hline & & 7.8 & $\begin{array}{l}\text { Valine, isoleucine, phenylalanine, } \\
\text { histidine, leucine, arginine }\end{array}$ & $313^{d}$ & 0.06 & $-0.97^{d}$ & \\
\hline \multirow[t]{2}{*}{ 75 95} & 14.7 & 10.1 & Valine, isoleucine, alanine & 170 & 0.14 & -0.63 & Zhang et al. [19] \\
\hline & & 10.2 & Valine, isoleucine, leucine & 90 & 0.14 & -0.18 & \\
\hline
\end{tabular}

aAnalyzed values; "!" means data were not provided in the paper

${ }^{\mathrm{b}}$ Additional supplemented AA in LP diets except FCAA; “-" means no other CAA supplemented except FCAA

${ }^{\mathrm{C}} \mathrm{ADG}=\mathrm{ADG}$ (control diet)- ADG (LP diet); ADFI = ADFI (control diet)- ADFI (LP diet); F:G = F:G (control diet)- F:G (LP diet)

${ }^{d}$ Values were significant different between LP diet and control diet

protein-bound AA was reported to be a more effective strategy to maintain nitrogen retention and whole body protein homeostasis than free AA [40]. Moreover, the content of di- and tri-peptides hydrolyzed from intact protein was reported to be positively correlated with the activities of digestive enzymes [84]. The more rapid absorption rates of free AA may induce excessive oxidation of AA contributing to the decreased body protein deposition and poor growth performance [85].

Discrepancies of growth performance caused by LP diets between the above studies may be due to variations of CP levels designed for the control diets, types of feed ingredients, feeding pattern (restricted vs. ad libitum feed intake) and experimental conditions. In general, the first four limiting AA should be supplemented when the $\mathrm{CP}$ reduction is below $3 \%$, additional supplementation with BCAA could maintain similar growth performance compared with control group with up to a $6 \%$ reduction. Further reduction (more than $6 \%$ reduction of $\mathrm{CP}$ content) will require inclusion of dietary nitrogen or sufficient NEAA to ameliorate the poor growth performance.

\section{Carcass characteristic}

It's debatable whether LP diets supplemented with CAA affect carcass characteristics. Dressing percentage is the ratio of carcass weight to pre-slaughter live weight and is not affected by reducing dietary CP level $[9,86,87]$. However, increased back-fat thickness and reduced loin muscle area at slaughter were consistently reported in LP diets studies $[4,88,89]$, in fattening pigs as well as growing pigs $[10,90]$. Three reasons may be responsible for this observation: 1) more energy is required for excretion of excess AA in the HP diet. In contrast, LP diet are closer to the ideal protein ratio which would reduce energy needed for $\mathrm{N}$ excretion leaving more energy to be deposited in adipose tissue [91]; 2) the relative weight of liver, intestine, kidney and pancreas increases in HP diets which increases maintenance energy needs [81, 88]; 3) the relatively greater proportion of cereal grains in a LP diet results in a high content of available starch which is more efficient for fat deposition than AA [92]. To alleviate the negative effects on carcass characteristic of LP diets, many researches had been conducted. Supplementation with some functional AA have shown potential to reduce excessive body fat (e.g. leucine, 
arginine, glutamine, glutamate, and proline) [93]. Leucine, a BCAA, is reported to be an effectively AA to regulate protein synthesis through the mammalian target of rapamycin (mTOR)-dependent process [94]. Zhang et al. [19] showed that the supplementation of $0.40 \% \mathrm{~L}$-leucine to a LP diet (CP 10\%, SID leucine: lysine $=1.05)$ increased tissue protein synthesis and improve the carcass characteristic of finishing pigs more than an alanine-supplemented diet when compared with the control diet (14.5\%). Some studies have demonstrated that dietary arginine, a semi-essential AA, may reduce fat deposition and stimulate protein synthesis by regulating metabolism of energy substrates through production of NO [95]. However, an imbalance of energy to nitrogen may be the primary reason for the fatter carcass in pigs fed LP diets. The NE system (in comparison with digestible energy (DE) or metabolizable energy (ME) systems) has been confirmed to be superior for controlling carcass adiposity and will be detailed in the following sections.

\section{Meat quality}

Meat quality is primarily assessed by the following sensory traits: color, $\mathrm{pH}$, marbling (intramuscular fat (IMF) content), tenderness (shearing force), water holding capacity (WHC; drip loss, purge loss, cooking loss), and juiciness [96]. Most studies reported no significant difference in $\mathrm{pH}_{24} \mathrm{~h}$ and $\mathrm{WHC}$ in pigs fed different dietary CP $[97,98]$. Some variables $\left(\mathrm{L}^{\prime \prime}, \mathrm{a}^{\prime \prime}, \mathrm{b}\right.$ ", C $\mathrm{C}^{\prime \prime}$ and $\mathrm{H}^{0}$ ) of meat color increased when dietary $\mathrm{CP}$ was restricted $[87,97]$. Nevertheless, other studies reported no differences were observed in $\mathrm{L}^{\text {" }}$ between treatments $[98,99]$. Zanardi et al. [100] suggested that human perception of pork color is strictly linked with lightness and hue angle which are typically affected by $\mathrm{pH}$ and WHC, while redness and chroma appear to be less important. Recent studies suggested a tendency towards greater fat deposition in pigs fed with LP diets from 40 to $115 \mathrm{~kg} \mathrm{BW}$, concomitantly pork that was more tender and juicy was reported [101]. Suárez-Belloch et al. [87] also observed that dietary $\mathrm{CP}$ restriction during the growing period improved some traits related to meat quality, such as decreasing the hardness and tending to increase the IMF content which was desirable for heavy pigs intended for dry-cured products. In the study of Teye et al. [102], marbling fat in longissimus dorsi muscle was $2.9 \%$ in pigs fed LP diets compared with $1.7 \%$ in pigs fed HP diets and the backfat thickness was similar between LP and HP-fed pigs. Scores of tenderness and juiciness were also markedly increased in pigs fed LP diets by 0.6 units and 0.5 units, respectively. A higher percentage of oleic acid and a lower percentage of linoleic acid in both longissimus and semimembranosus muscles were determined in LP diets which suggest an improved eating quality [101].
These sensory traits of meat quality are mainly dependent on two related biological processes including muscle growth and deposition of fat [103].

Muscle growth reflects protein accretion which is a balance between the rates of protein synthesis and degradation [104]. The mammalian target of rapamycin complex 1 (mTORC1) pathway plays a decisive role in controlling protein synthesis [105]. The mTORC1 pathway includes the following components, Raptor: an adaptor to recruit substrates to the mTOR protein; 4E-BP1 and S6 K1: two of the most characterized substrates for the mTORC1 pathway, activation of the pathway promotes protein translation and increases cell growth [106]. Accumulating data demonstrates there is a positive relationship between dietary $\mathrm{CP}$ level and mTOR signaling of muscle protein synthesis in pigs [107]. At present, the process of protein degradation as influenced by protein levels has received much less attention. Zhou et al. [86] observed the mRNA abundance of FOXO, MAFbx and MuRF1 that included in the ubiquitin-proteasome pathway (UPP) was not influenced when the $\mathrm{CP}$ level reduced from $14 \%$ to $10 \%$ in growing pigs. The UPP is the primary intracellular system for protein degradation in skeletal muscle, which implied that the proteolysis of skeletal muscle was not affected by the dietary protein restriction. Moreover, dietary BCAA supplementation enhanced muscle mass due to a greater increase in protein synthesis than protein degradation [104].

Fat is an important contributor to various aspects of meat quality [103]. However, fat is also considered an unhealthy constituent for many consumers [108]. Therefore, manipulation of the fatty acid composition of muscle and fatty tissues has achieved great interest in the last decades. Intramuscular fat has been reduced to below $1 \%$ of muscle weight in modern pigs through the genetic selection which has simultaneously harmed the sensory trait of pork because of a direct relationship between IMF and the formation of tenderness, juiciness, marbling, and the flavor of cooked meat [98]. Therefore, consumers are becoming increasingly interested in meat containing high concentration of IMF and polyunsaturated fatty acids (PUFA) [109], as seen that pigs fed with LP diets dramatically enhance the content of IMF in growing or finishing phases [12, 101]. Growing-finishing pigs fed a LP diet showed a high content of IMF in the longissimus thoracis muscle. In addition, supplementation with antioxidants like essential oil and benzoic acid further decreased the degradation of lipids in muscles [110]. A study conducted in two different genotypes further suggested that dietary $\mathrm{CP}$ regulated lipid anabolism and catabolism via modulation of the mRNA levels of key regulatory enzymes and fatty acid transport proteins in different muscle tissues [103]. 
Taken together, although an appropriate reduction of CP level would increase the IMF content and tenderness score, consequently ameliorating the meat quality concern, the reduction in protein synthesis and leanness is out of our expectation. Therefore, further research on the underlying mechanisms of how LP diets influence the meat quality need to be conducted.

\section{The effects of LP diets on nutrient digestibility}

In digestibility studies, digestibility of different nutrients has generally been evaluated separately, because the relationship between the digestibility of these nutrients is complicated making it hard to determine the interactive effects. However, some attempts had been made to reveal the complex interaction.

It has been generally assumed that AA and phosphorus $(\mathrm{P})$ digestion and absorption were independent in swine; for example, dietary CP concentration was not considered in the studies of $\mathrm{P}$ digestibility. However, AA and $\mathrm{P}$ are two key regulators and components to the skeletal muscle growth and gene expression of the active transporter of $\mathrm{P}$ in the small intestine is limited by $\mathrm{CP}$ restriction [111]. Moreover, Xue et al. [112] indicated that the content of ileal digested P decreased in the LP diet compared with the HP diet of growing pigs, which indicate a limiting effect of dietary $\mathrm{CP}$ level on ileal P digestion. A possible reason may be that limited protein intake impaired the active transportation system of $\mathrm{P}$.

An earlier study reported higher ileal digestibility of fat and saturated fatty acids 14:0 and 18:0 with increasing dietary CP [113]. However, other studies reported a lower digestibility of crude fat with increasing dietary $\mathrm{CP}$ concluding that free fatty acids can bind with undigested protein to form micelles that are unavailable for absorption [114]. In addition, the relative proportion of endogenous fat excretion into the intestine increased in HP diets may affect the apparent digestibility of fat.

There have been no studies specifically evaluating the effect of LP diets on fiber digestibility; whereas many studies have demonstrated that fiber and LP diets have synergetic effects on gut health [24]. Therefore, the influence of LP diets on the digestion of fiber should be determined.

\section{The nutrient balance of LP diets}

The NE requirement and the ratio of NE to lysine for LP diets The most concerning challenge of LP diets supplemented with CAA on pig production is the increase in back-fat at slaughter $[4,9]$ and may be partially due to more dietary energy being available for fat deposition. The reduction in deamination of excess AA and nitrogen and thus, less heat production, reduces overall energy expenditure [11, 91]. The DE or ME system over-estimates the available energy of protein and simultaneously underestimates starch energy availability. The proportional value of NE/ME for protein is $60 \%$ compared with $80 \%$ for starch [115]. Chen et al. [116] reported that NE is the only system where energy requirements of the animal and available energy of all feed types can be expressed on the same basis. Therefore, the NE system may be more suitable for LP diets and would help to inhibit excessive carcass fat deposition. Le Bellego et al. [117] confirmed the superiority of using the $\mathrm{NE}$ system in diets with variable $\mathrm{CP}$ contents by measuring the growth performance and carcass adiposity in comparison with DE or ME systems. However, accurate measurement of the NE value of feedstuff was still be a part of the problem that hampers the application of the NE system, because the NE is harder and more difficult to determine than DE and ME for pigs [116].

Yi [118] conducted eight experiments to investigate the requirements of NE for growing and finishing pigs fed LP diets supplemented with CAA. The first four experiments indicated that the optimal NE level was $2.36 \mathrm{Mcal} / \mathrm{kg}$ and $2.40 \mathrm{Mcal} / \mathrm{kg}$ for growing and finishing pigs calculated using both the broken-line model and quadratic regression analysis with maximum performance and carcass characteristics, respectively. The following two experiments suggested the best ratio of lysine to NE was $4.70 \mathrm{~g} / \mathrm{Mcal}$ and $3.50 \mathrm{~g} / \mathrm{Mcal}$ when dietary CP was reduced by four percentage units for growing and finishing pigs, respectively. Recommendation requirements from the six previous experiments have been validated in commercial conditions in two subsequent experiments. To the best of our knowledge, this study is the only comprehensive evaluation of the optimal NE levels in LP diets for pigs in different growing phases under commercial conditions.

\section{The AA balance requirements of SID AA in LP diets}

To eliminate the invalid fermentation of AA in hindgut and higher correlation was observed between both daily gain and feed efficiency with ileal AA digestibility than fecal values, ileal digestibility is more suitable than total tract digestibility for AA bioavailability. Moreover, SID AA is widely used because the contribution of basal endogenous losses are quantified and more likely to be additive in mixed diets, thus, it is more accurate than apparent ileal digestible (AID) values [119]. The NRC (2012) [8] has published the SID AA requirements in different growing phases of pigs with ad libitum feed access. However, the recommended AA needs were determined using a prediction model and limited empirical studies have been conducted to validate the values. In addition, the estimates are based on traditional dietary CP concentrations that may be inconsistent with CP levels common in LP diets. Therefore, a precise measurement of the appropriate SID AA requirements when pigs are fed LP diets could maximize the advantages of LP diets and simultaneously optimize the cost of supplemental CAA. 
The SID AA requirements of pigs are expressed as the AA to lysine ratio and estimated using dose-response studies representing the sum of those for body maintenance functions and protein retention [8]. When determining the AA requirements (except lysine), lysine should be at a suboptimal level (second limiting) after the tested AA which should be tested with at least four different gradient levels [120]. Performance, carcass traits, serum AA concentrations and SUN are used as the response criteria for growing pigs [121] and the 'best' criteria should base on the specific experiment. For instance, growth performance is better for growing period, carcass traits are better for fattening period, serum AA can be used to validate estimates and SUN has been used as a rapid response criterion [122]. In dose-response studies, the choice of statistical method used to interpret the data is critical. The most widely used models include the linear-broken line analysis and the quadratic model each with its advantages and disadvantages, which have been completely summarized by Robbins et al. [123].

The order of the first four limiting EAA is lysine, threonine, tryptophan and SAA in CSBM based LP diets according to the extent of additional supplemented CAA compared with the HP diet. This order is a little different from the NRC (2012) [8] recommendations with a sequence of lysine, SAA, threonine and tryptophan [124, 125]. Moreover, recent studies showed that besides these four EAA, valine can also contribute to the improvement of growth performance as the fifth limiting AA [122].

Many of the studies on requirements for these five EAA in pigs fed LP diets across the entire growth phases for commercial pigs have been completed by our group [124-129]. Appropriate requirements of CP, $\mathrm{NE}$, and SID AA in growing pigs fed with LP diets based on these studies determined in China are summarized in Table 2. The recommended requirements of SID AA determined in these studies were slightly higher than corresponding NRC (2012) [8] recommendations, indicating that more nitrogen from CAA is utilized for the synthesis of deficient NEAA than when pigs are fed normal protein diets. In addition, these studies have been primarily conducted under commercial conditions and are more applicable for pig production than the NRC (2012) [8] requirements determined under laboratory conditions or model derived. Moreover, our unpublished data had been confirmed the recommended requirements of Table 2 were applicable in commercial pig farms in China.

\section{Conclusion}

The application of LP diets is a tool in pig production not only to reduce feed costs and nitrogen excretion but also to effectively improve gut health in an era of increasing antibiotic use limitations. Reducing CP level by
Table 2 Dietary protein, NE and SID EAA requirements of growing pigs $^{\text {a }}$

\begin{tabular}{lllll}
\hline Item & \multicolumn{4}{l}{ Body weight range, $\mathrm{kg}$} \\
\cline { 2 - 5 } & $7-20$ & $20-50$ & $50-80$ & $80-110$ \\
\hline Crude protein, \% $^{\prime}$ & 18 & 15 & 13 & 12 \\
NE content ${ }^{\mathrm{b}}$, kcal/kg & 2450 & 2360 & 2360 & 2400 \\
Amino acids, standardized ileal digestible basis, \% & & \\
Lysine & 1.30 & 1.01 & 0.86 & 0.75 \\
Threonine & 0.84 & 0.65 & 0.54 & 0.49 \\
Tryptophan & 0.26 & 0.18 & 0.15 & 0.13 \\
Methionine + Cysteine & 0.75 & 0.58 & 0.50 & 0.43 \\
Valine & 0.78 & 0.63 & 0.56 & 0.51 \\
Ratio of SID AA to SID lysine & & & & \\
Threonine/Lysine & 0.65 & 0.64 & 0.63 & 0.65 \\
Tryptophan/Lysine & 0.20 & 0.18 & 0.17 & 0.17 \\
(Methionine+ Cysteine)/Lysine & 0.58 & 0.57 & 0.58 & 0.57 \\
Valine/Lysine & 0.60 & 0.62 & 0.65 & 0.68 \\
\hline
\end{tabular}

${ }^{\mathrm{a}}$ The recommended requirements summarized from the academic dissertation of our research group determined in China [118, 124-129]

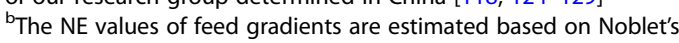
equations [115]

three to four percentages and supplementing with crystalline lysine, threonine, tryptophan, methionine and valine yields no negative effects on animal performance or nitrogen retention. The challenge of fatter carcasses generated by LP diets may be avoided by adoption of the $\mathrm{NE}$ system and balanced AA. However, concomitantly increased IMF content when pigs are fed LP diets could improve the eating experience required a novel proposition that how to increase IMF content in the case of thin backfat thickness. Thus, the underlying mechanism of how LP diets affect protein and fat metabolism should be elucidated, in order to provide a nutritional strategy improves the meat quality. With the development of biological fermentation technology, a greater range in CAA is available for feed use; therefore, a further reduction of dietary $\mathrm{CP}$ would be possible but routine implementation requires verification of the feasibility and practical significance.

\section{Abbreviations}

AA: Amino acids; AID: Apparent ileal digestible; AMR: Antimicrobial resistance; BCAA: Branched-chain amino acids; BCFAs: Branched-chain fatty acids; CAA: Crystalline amino acids; CD4: Cluster of differentiation 4; CP: Crude protein; CSBM: Corn-soybean meal; DDGS: Distillers dried grains with soluble; DE: Digestible energy; EAA: Essential amino acids; ETEC: Enterotoxigenic Escherichia coll; E. coli: Escherichia coli; FCAA: Four crystalline amino acids; GIT: Gastro-intestinal tract; GSH: Glutathione; Hcy: Homocysteine; HP: High-protein; IFNy: Interferon Y; IgG: Immunoglobulin G; IMF: Intramuscular fat; LP: Low-protein; ME: Metabolizable energy; mTOR: Mammalian target of rapamycin; mTORC1: Mammalian target of rapamycin complex 1; NCG: N-carbamylglutamate; NE: Net energy; NEAA: Non-essential amino acids; NO: Nitric oxide; P: Phosphorus; PUFA: Polyunsaturated fatty acids; PUN: Plasma urea nitrogen; PWD: Postweaning diarrhea; SAA: Sulfur amino acids; SBM: Soybean meal; SCFAs: Short- 
chain fatty acids; SID: Standardized ileal digestible; SUN: Serum urea nitrogen; TID: True ileal digestible; TNFa: Tumor necrosis factor a; UPP: Ubiquitinproteasome pathway; VLP: Very low-protein; WHC: Water holding capacity

\section{Acknowledgements}

The author would like to thank Dr. L. J. Johnston and Dr. C. Levesque for their help.

\section{Funding}

This work was financially supported by the Beijing Swine Innovation Team of Modern Agriculture Industry Technological System, and Beijing Advanced Innovation Center for Food Nutrition and Human Health, College of China Agricultural University.

\section{Availability of data and materials}

Please contact author for data requests.

\section{Authors' contributions}

YW initiated the purpose, the scope, and the outline of this review paper. SQ critically revised the manuscript. YW, JZ, GW, SC, XZ and SQ studied all of the publications cited in this paper, and approved the final manuscript.

\section{Ethics approval and consent to participate}

All procedures used in experiments of our lab were performed in accordance with the China Agricultural University Animal Care and Use Committee guidelines (ID: SKLAB-B-2010-003).

\section{Consent for publication}

Not applicable.

\section{Competing interests}

The authors declare that they have no competing interests.

Received: 17 December 2017 Accepted: 21 June 2018

\section{Published online: 19 July 2018}

\section{References}

1. Gloaguen M, Le Floc'H N, Corrent E, Primot Y, van Milgen J. The use of free amino acids allows formulating very low crude protein diets for piglets. J Anim Sci. 2014;92:637-44.

2. Houmard NM, Mainville JL, Bonin CP, Huang S, Luethy MH, Malvar TM. Highlysine corn generated by endosperm-specific suppression of lysine catabolism using RNAi. Plant Biotechnol J. 2007;5:605-14.

3. National Research Council (NRC). Nutrient requirements of swine. Washington DC, USA: National Academy Press; 1998.

4. Kerr BJ, Southern LL, Bidner TD, Friesen KG, Easter RA. Influence of dietary protein level, amino acid supplementation, and dietary energy levels on growing-finishing pig performance and carcass composition. J Anim Sci. 2003:81:3075-87.

5. Nyachoti CM, Omogbenigun FO, Rademacher M, Blank G. Performance responses and indicators of gastrointestinal health in early-weaned pigs fed low-protein amino acid-supplemented diets. J Anim Sci. 2006;84:125-34.

6. Yue L, Qiao S. Effects of low-protein diets supplemented with crystalline amino acids on performance and intestinal development in piglets over the first 2 weeks after weaning. Livest Sci. 2008;115:144-52.

7. Fan $\mathrm{P}$, Liu $\mathrm{P}$, Song $\mathrm{P}$, Chen $\mathrm{X}$, Ma X. Moderate dietary protein restriction alters the composition of gut microbiota and improves ileal barrier function in adult pig model. Sci Rep-Uk. 2017;7:43412.

8. National Research Council (NRC). Nutrient requirements of swine. Washington DC, USA: National Academy Press; 2012.

9. Kerr BJ, McKeith FK, Easter RA. Effect on performance and carcass characteristics of nursery to finisher pigs fed reduced crude protein, amino acid-supplemented diets. J Anim Sci. 1995;73:433-40.

10. Tuitoek K, Young LG, De Lange CF, Kerr BJ. The effect of reducing excess dietary amino acids on growing-finishing pig performance: an elevation of the ideal protein concept. J Anim Sci. 1997;75:1575-83.

11. Yi X, Zhang S, Yang Q, Yin H, Qiao S. Influence of dietary net energy content on performance of growing pigs fed low crude protein diets supplemented with crystalline amino acids. J Swine Health Prod. 2010;18: 294-300.
12. Tous N, Lizardo R, Vilà B, Gispert M, Font-i-Furnols M, Esteve-Garcia E. Effect of reducing dietary protein and lysine on growth performance, carcass characteristics, intramuscular fat, and fatty acid profile of finishing barrows. J Anim Sci. 2014;92:129-40.

13. Zhang $\mathrm{Q}$, Reed $\mathrm{M}$. Examining the impact of the world crude oil price on China's agricultural commodity prices: The case of corn, soybean, and pork, The Southern Agricultural Economics Association Annual Meetings, Dallas, TX; 2008. p. 2008.

14. Patience JF. Managing energy intake and costs of grow-finish pigs. Adv Pork Prod. 2013:4:29-35.

15. Woyengo TA, Beltranena E, Zijlstra RT. Nonruminant nutrition symposium: controlling feed cost by including alternative ingredients into pig diets: a review. J Anim Sci. 2014;92:1293-305.

16. Zhang G, Yi X, Lu N, Qiao S. Effects of low protein diet formulated by net energy system on growth performance and carcass characteristic of growing and finishing pigs. Chin J Anim Nutr. 2010;22:557-63.

17. Webb J, Broomfield M, Jones S, Donovan B. Ammonia and odour emissions from UK pig farms and nitrogen leaching from outdoor pig production. A review. Sci Total Environ. 2014;470:865-75.

18. Aarnink A, Verstegen M. Nutrition, key factor to reduce environmental load from pig production. Livest Sci. 2007;109:194-203.

19. Zhang S, Chu L, Qiao S, Mao X, Zeng X. Effects of dietary leucine supplementation in low crude protein diets on performance, nitrogen balance, whole-body protein turnover, carcass characteristics and meat quality of finishing pigs. Anim Sci J. 2016;87:911-20.

20. Kohn RA, Dinneen MM, Russek-Cohen E. Using blood urea nitrogen to predict nitrogen excretion and efficiency of nitrogen utilization in cattle, sheep, goats, horses, pigs, and rats. J Anim Sci. 2005;83:879-89.

21. Hayes ET, Leek ABG, Curran TP, Dodd VA, Carton OT, Beattie VE, et al. The influence of diet crude protein level on odour and ammonia emissions from finishing pig houses. Bioresour Technol. 2004;91:309-15.

22. Leek A, Hayes E, Curran T, Callan J, Beattie V, Dodd V, et al. The influence of manure composition on emissions of odour and ammonia from finishing pigs fed different concentrations of dietary crude protein. Bioresour Technol. 2007;98:3431-9.

23. Eriksen J, Adamsen APS, Nørgaard JV, Poulsen HD, Jensen BB, Petersen SO Emissions of sulfur-containing odorants, ammonia, and methane from pig slurry: effects of dietary methionine and benzoic acid. J Environ Qual. 2010; 39:1097-107.

24. Rist VTS, Weiss E, Eklund M, Mosenthin R. Impact of dietary protein on microbiota composition and activity in the gastrointestinal tract of piglets in relation to gut health: a review. Animal. 2013;7:1067-78.

25. Cromwell GL. Why and how antibiotics are used in swine production. Anim Biotechnol. 2002;13:7-27.

26. Pluske JR, Pethick DW, Hopwood DE, Hampson DJ. Nutritional influences on some major enteric bacterial diseases of pig. Nutr Res Rev. 2002;15:333-71.

27. Neis EP, Dejong CH, Rensen SS. The role of microbial amino acid metabolism in host metabolism. Nutrients. 2015;7:2930-46.

28. Portune KJ, Beaumont M, Davila A, Tomé D, Blachier F, Sanz Y. Gut microbiota role in dietary protein metabolism and health-related outcomes: the two sides of the coin. Trends Food Sci Technol. 2016;57:213-32.

29. Nieuwdorp M, Gilijamse PW, Pai N, Kaplan LM. Role of the microbiome in energy regulation and metabolism. Gastroenterology. 2014;146:1525-33.

30. Pieper R, Tudela CV, Taciak M, Bindelle J, Pérez JF, Zentek J. Health relevance of intestinal protein fermentation in young pigs. Anim Health Res Rev. 2016;17:137-47.

31. Macfarlane GT, Macfarlane S. Bacteria, colonic fermentation, and gastrointestinal health. J AOAC Int. 2012;95:50-60.

32. Andriamihaja M, Davila A, Eklou-Lawson M, Petit N, Delpal S, Allek F, et al. Colon luminal content and epithelial cell morphology are markedly modified in rats fed with a high-protein diet. Am J Physiol-Gastr L. 2010;299: G1030-7.

33. Macfarlane GT, Gibson GR. Microbiological aspects of the production of short-chain fatty acids in the large bowel. Physiological and clinical aspects of short-chain fatty acids; 1995. p. 87-105.

34. Yun JH, Kwon IK, Lohakare JD, Choi JY, Yong JS, Zheng J, et al. Comparative efficacy of plant and animal protein sources on the growth performance, nutrient digestibility, morphology and caecal microbiology of early-weaned pigs. Asian Australas J Anim Sci. 2005;18:1285-93.

35. Heo JM, Opapeju FO, Pluske JR, Kim JC, Hampson DJ, Nyachoti CM. Gastrointestinal health and function in weaned pigs: a review of feeding 
strategies to control post-weaning diarrhoea without using in-feed antimicrobial compounds. J Anim Physiol Anim Nutr. 2013;97:207-37.

36. Heo J, Kim J, Hansen CF, Mullan BP, Hampson DJ, Pluske JR. Effects of feeding low protein diets to piglets on plasma urea nitrogen, faecal ammonia nitrogen, the incidence of diarrhoea and performance after weaning. Arch Anim Nutr. 2008;62:343-58.

37. Heo JM, Kim JC, Hansen CF, Mullan BP, Hampson DJ, Pluske JR. Feeding a diet with decreased protein content reduces indices of protein fermentation and the incidence of postweaning diarrhea in weaned pigs challenged with an enterotoxigenic strain of Escherichia coli. J Anim Sci. 2009;87:2833-43.

38. Lordelo MM, Gaspar AM, Le Bellego L, Freire JPB. Isoleucine and valine supplementation of a low-protein corn-wheat-soybean meal-based diet for piglets: growth performance and nitrogen balance. J Anim Sci. 2008;86: 2936-41.

39. Bhandari SK, Opapeju FO, Krause DO, Nyachoti CM. Dietary protein level and probiotic supplementation effects on piglet response to Escherichia coli K88 challenge: performance and gut microbial population. Livest Sci. 2010;133:185-8.

40. Guay F, Donovan SM, Trottier NL. Biochemical and morphological developments are partially impaired in intestinal mucosa from growing pigs fed reduced-protein diets supplemented with crystalline amino acids. J Anim Sci. 2006;84:1749-60

41. Opapeju FO, Rademacher M, Blank G, Nyachoti CM. Effect of low-protein amino acid-supplemented diets on the growth performance, gut morphology, organ weights and digesta characteristics of weaned pigs. Animal. 2008;2:1457-64.

42. Opapeju FO, Krause DO, Payne RL, Rademacher M, Nyachoti CM. Effect of dietary protein level on growth performance, indicators of enteric health, and gastrointestinal microbial ecology of weaned pigs induced with postweaning colibacillosis. J Anim Sci. 2009;87:2635-43.

43. Collins SM, Surette M, Bercik P. The interplay between the intestinal microbiota and the brain. Nat Rev Microbiol. 2012;10:735-42.

44. Lee W, Hase K. Gut microbiota-generated metabolites in animal health and disease. Nat Chem Biol. 2014;10:416-24.

45. Libao-Mercado AJO, Zhu CL, Cant JP, Lapierre H, Thibault J, Sève B, et al. Dietary and endogenous amino acids are the main contributors to microbial protein in the upper gut of normally nourished pigs. J Nutr. 2009; 139:1088-94.

46. Pieper R, Kröger S, Richter JF, Wang J, Martin L, Bindelle J, et al. Fermentable fiber ameliorates fermentable protein-induced changes in microbial ecology, but not the mucosal response, in the colon of piglets. J Nutr. 2012; 142:661-7.

47. Luo Z, Li C, Cheng Y, Hang S, Zhu W. Effects of low dietary protein on the metabolites and microbial communities in the caecal digesta of piglets. Arch Anim Nutr. 2015;69:212-26.

48. Bikker P, Dirkzwager A, Fledderus J, Trevisi P. The effect of dietary protein and fermentable carbohydrates levels on growth performance and intestinal characteristics in newly weaned piglets. J Anim Sci. 2006;84:3337-45.

49. Zhou L, Fang L, Sun Y, Su Y, Zhu W. Effects of the dietary protein level on the microbial composition and metabolomic profile in the hindgut of the pig. Anaerobe. 2016;38:61-9.

50. Konstantinov SR, Favier CF, Zhu WY, Williams BA, Klüß J, Souffrant W, et al. Microbial diversity studies of the porcine gastrointestinal ecosystem during weaning transition. Anim Res. 2004:53:317-24.

51. Dai Z, Zhang J, Wu G, Zhu W. Utilization of amino acids by bacteria from the pig small intestine. Amino Acids. 2010;39:1201-15.

52. Ma X, Sun P, He P, Han P, Wang J, Qiao S, et al. Development of monoclonal antibodies and a competitive ELISA detection method for glycinin, an allergen in soybean. Food Chem. 2010;121:546-51.

53. Li D, Nelssen JL, Reddy PG, Blecha F, Klemm R, Goodband RD. Interrelationship between hypersensitivity to soybean proteins and growth performance in early-weaned pigs. J Anim Sci. 1991;69:4062-9.

54. Zuercher AW, Fritsche R, Corthésy B, Mercenier A. Food products and allergy development, prevention and treatment. Curr Opin Biotechnol. 2006; 17:198-203.

55. Wu G, Ott TL, Knabe DA, Bazer FW. Amino acid composition of the fetal pig J Nutr. 1999:129:1031-8.

56. Kim SW, Mateo RD, Yin Y, Wu G. Functional amino acids and fatty acids for enhancing production performance of sows and piglets. Asian Australas J Anim Sci. 2007;20:295-306.
57. Wang W, Zeng X, Mao X, Wu G, Qiao S. Optimal dietary true ileal digestible threonine for supporting the mucosal barrier in small intestine of weanling pigs. J Nutr. 2010;140:981-6.

58. van der Meer $Y$, Lammers A, Jansman AJM, Rijnen MMJA, Hendriks WH, Gerrits WJJ. Performance of pigs kept under different sanitary conditions affected by protein intake and amino acid supplementation. J Anim Sci. 2016;94:4704-19.

59. Wang X, Qiao S, Yin Y, Yue L, Wang Z, Wu G. A deficiency or excess of dietary threonine reduces protein synthesis in jejunum and skeletal muscle of young pigs. J Nutr. 2007;137:1442-6.

60. Xie C, Zhang S, Zhang G, Zhang F, Chu L, Qiao S. Estimation of the optimal ratio of standardized ileal digestible threonine to lysine for finishing barrows fed low crude protein diets. Asian Australas J Anim Sci. 2013;26:1172-80.

61. Li P, Yin Y, Li D, Woo Kim S, Wu G. Amino acids and immune function. Brit Nutr. 2007;98:237-52

62. Bauchart-Thevret C, Stoll B, Chacko S, Burrin DG. Sulfur amino acid deficiency upregulates intestinal methionine cycle activity and suppresses epithelial growth in neonatal pigs. Am J Physiol-Endoc M. 2009:296:E1239-50.

63. Rakhshandeh A, Htoo JK, de Lange C. Immune system stimulation of growing pigs does not alter apparent ileal amino acid digestibility but reduces the ratio between whole body nitrogen and sulfur retention. Livest Sci. 2010;134:21-3.

64. Platten M, Ho PP, Youssef S, Fontoura P, Garren H, Hur EM, et al. Treatment of autoimmune neuroinflammation with a synthetic tryptophan metabolite. Science. 2005;310:850-5.

65. Trevisi P, Melchior D, Mazzoni M, Casini L, De Filippi S, Minieri L, et al. A tryptophan-enriched diet improves feed intake and growth performance of susceptible weanling pigs orally challenged with Escherichia coli K88. J Anim Sci. 2009:87:148-56.

66. Zhang G, Song Q, Xie C, Chu L, Thacker PA, Htoo JK, et al. Estimation of the ideal standardized ileal digestible tryptophan to lysine ratio for growing pigs fed low crude protein diets supplemented with crystalline amino acids. Livest Sci. 2012;149:260-6.

67. Self JT, Spencer TE, Johnson GA, Hu J, Bazer FW, Wu G. Glutamine synthesis in the developing porcine placenta. Biol Reprod. 2004;70:1444-51.

68. Zhang S, Zeng X, Ren M, Mao X, Qiao S. Novel metabolic and physiological functions of branched chain amino acids: a review. J Anim Sci Biotechno. 2017:8:10.

69. Ren M, Zhang S, Zeng X, Liu H, Qiao S. Branched-chain amino acids are beneficial to maintain growth performance and intestinal immune-related function in weaned piglets fed protein restricted diet. Asian Australas J Anim Sci. 2015;28:1742-50.

70. Kidd MT, Kerr BJ, Anthony NB. Dietary interactions between lysine and threonine in broilers. Poult Sci. 1997:76:608-14.

71. Wu G, Meininger CJ, Knabe DA, Baze FW, Rhoads JM. Arginine nutrition in development, health and disease. Curr Opin Clin Nutr Metab Care. 2000;3:59-66

72. Liu Y, Huang J, Hou Y, Zhu H, Zhao S, Ding B, et al. Dietary arginine supplementation alleviates intestinal mucosal disruption induced by Escherichia coli lipopolysaccharide in weaned pigs. Brit J Nutr. 2008;100: 552-60

73. Frank JW, Escobar J, Nguyen HV, Jobgen SC, Jobgen WS, Davis TA, et al. Oral N-carbamylglutamate supplementation increases protein synthesis in skeletal muscle of piglets. J Nutr. 2007:137:315-9.

74. Zeng X, Huang Z, Mao X, Wang J, Wu G, Qiao S. N-carbamylglutamate enhances pregnancy outcome in rats through activation of the PI3K/PKB/ mTOR signaling pathway. PLoS One. 2012;7:e41192.

75. Zhang F, Zeng X, Yang F, Huang Z, Liu H, Ma X, et al. Dietary Ncarbamylglutamate supplementation boosts intestinal mucosal immunity in escherichia coli challenged piglets. PLoS One. 2013;8:e66280.

76. Jha R, Berrocoso JFD. Dietary fiber and protein fermentation in the intestine of swine and their interactive effects on gut health and on the environment: a review. Anim Feed Sci Technol. 2016:212:18-26.

77. Prandini A, Sigolo S, Morlacchini M, Grilli E, Fiorentini L. Microencapsulated lysine and low-protein diets: effects on performance, carcass characteristics and nitrogen excretion in heavy growing-finishing pigs. J Anim Sci. 2013;91: 4226-34.

78. Roux ML, Donsbough AL, Waguespack AM, Powell S, Bidner TD, Payne RL, et al. Maximizing the use of supplemental amino acids in corn-soybean meal diets for 20- to 45-kilogram pigs. J Anim Sci. 2011;89:2415-24. 
79. Powell S, Bidner TD, Payne RL, Southern LL. Growth performance of 20- to 50-kilogram pigs fed low-crude-protein diets supplemented with histidine, cystine, glycine, glutamic acid, or arginine. J Anim Sci. 2011;89:3643-50.

80. Zheng L, Wei H, Cheng C, Xiang Q, Pang J, Peng J. Supplementation of branched-chain amino acids to a reduced-protein diet improves growth performance in piglets: involvement of increased feed intake and direct muscle growth-promoting effect. Brit J Nutr. 2016;115:2236-45.

81. Morales A, Buenabad L, Castillo G, Arce N, Araiza BA, Htoo JK, et al. Lowprotein amino acid-supplemented diets for growing pigs: effect on expression of amino acid transporters, serum concentration, performance, and carcass composition. J Anim Sci. 2015;93:2154-64.

82. Mansilla WD, Htoo JK, de Lange CFM. Nitrogen from ammonia is as efficient as that from free amino acids or protein for improving growth performance of pigs fed diets deficient in nonessential amino acid nitrogen. J Anim Sci. 2017:95:3093-102

83. Nemechek JE. Evaluation of compensatory gain, standardized ileal digestible lysine requirement, and replacing specialty protein sources with crystalline amino acids on growth performance of nursery pigs. Manhattan: M. S. Thesis. Kansas State Univ; 2011.

84. Shimizu M. Food-derived peptides and intestinal functions. Biofactors. 2004; 21:43-7.

85. Yen JT, Kerr BJ, Easter RA, Parkhurst AM. Difference in rates of net portal absorption between crystalline and protein-bound lysine and threonine in growing pigs fed once daily. J Anim Sci. 2004;82:1079-90.

86. Zhou P, Zhang L, Li J, Luo Y, Zhang B, Xing S, et al. Effects of dietary crude protein levels and cysteamine supplementation on protein synthetic and degradative signaling in skeletal muscle of finishing pigs. PLoS One. 2015; 10:e139393.

87. Suárez-Belloch J, Latorre MA, Guada JA. The effect of protein restriction during the growing period on carcass, meat and fat quality of heavy barrows and gilts. Meat Sci. 2016;112:16-23.

88. Ruusunen M, Partanen K, Pösö R, Puolanne E. The effect of dietary protein supply on carcass composition, size of organs, muscle properties and meat quality of pigs. Livest Sci. 2007;107:170-81.

89. Morazán H, Alvarez-Rodriguez J, Seradj AR, Balcells J, Babot D. Trade-offs among growth performance, nutrient digestion and carcass traits when feeding low protein and/or high neutral-detergent fiber diets to growingfinishing pigs. Anim Feed Sci Technol. 2015;207:168-80.

90. Hinson RB, Schinckel AP, Radcliffe JS, Allee GL, Sutton AL, Richert BT. Effect of feeding reduced crude protein and phosphorus diets on weaningfinishing pig growth performance, carcass characteristics, and bone characteristics. J Anim Sci. 2009;87:1502-17.

91. Smith JW, O'Quinn PR, Goodband RD, Tokach MD, Nelssen JL. Effects of low-protein, amino acid-fortified diets formulated on a net energy basis on growth performance and carcass characteristics of finishing pigs. J Appl Anim Res. 1999;15:1-16.

92. van Milgen J, Noblet J, Dubois S. Energetic efficiency of starch, protein and lipid utilization in growing pigs. J Nutr. 2001;131:1309-18.

93. Wu G. Functional amino acids in nutrition and health. Amino Acids. 2013;45: 407-11.

94. Zhang S, Ren M, Zeng X, He P, Ma X, Qiao S. Leucine stimulates ASCT2 amino acid transporter expression in porcine jejunal epithelial cell line (IPEC-J2) through PI3K/Akt/mTOR and ERK signaling pathways. Amino Acids. 2014:46:2633-42

95. Tan B, Yin Y, Liu Z, Tang W, Xu H, Kong X, et al. Dietary L-arginine supplementation differentially regulates expression of lipid-metabolic genes in porcine adipose tissue and skeletal muscle. J Nutr Biochem. 2011;22:441-5.

96. Grunert KG, Bredahl L, Brunsø K. Consumer perception of meat quality and implications for product development in the meat sector-a review. Meat Sci. 2004;66:259-72.

97. Goerl KF, Eilert SJ, Mandigo RW, Chen HY, Miller PS. Pork characteristics as affected by two populations of swine and six crude protein levels. J Anim Sci. 1995;73:3621-6.

98. Alonso V, Campo MDM, Provincial L, Roncalés P, Beltrán JA. Effect of protein level in commercial diets on pork meat quality. Meat Sci. 2010;85:7-14.

99. Bidner BS, Ellis M, Witte DP, Carr SN, McKeith FK. Influence of dietary lysine level, pre-slaughter fasting, and rendement napole genotype on fresh pork quality. Meat Sci. 2004;68:53-60.

100. Zanardi E, Novelli E, Ghiretti GP, Dorigoni V, Chizzolini R. Colour stability and vitamin E content of fresh and processed pork. Food Chem. 1999;67:163-71.

101. Wood JD, Lambe NR, Walling GA, Whitney $H$, Jagger S, Fullarton PJ, et al. Effects of low protein diets on pigs with a lean genotype: 1. Carcass composition measured by dissection and muscle fatty acid composition. Meat Sci. 2013:95:123-8.

102. Teye GA, Sheard PR, Whittington FM, Nute GR, Stewart A, Wood JD. Influence of dietary oils and protein level on pork quality. 1. Effects on muscle fatty acid composition, carcass, meat and eating quality. Meat Sci. 2006:73:157-65.

103. Liu Y, Li F, He L, Tan B, Deng J, Kong $X$, et al. Dietary protein intake affects expression of genes for lipid metabolism in porcine skeletal muscle in a genotype-dependent manner. Brit J Nutr. 2015;113:1069-77.

104. Zheng L, Wei H, He P, Zhao S, Xiang Q, Pang J, et al. Effects of supplementation of branched-chain amino acids to reduced-protein diet on skeletal muscle protein synthesis and degradation in the fed and fasted states in a piglet model. Nutrients. 2017:9:17.

105. Escobar J, Frank JW, Suryawan A, Nguyen HV, Kimball SR, Jefferson LS, et al. Physiological rise in plasma leucine stimulates muscle protein synthesis in neonatal pigs by enhancing translation initiation factor activation. Am J Physiol-Endoc M. 2005;288:E914-21.

106. Wullschleger $S$, Loewith $R$, Hall MN. TOR signaling in growth and metabolism. Cell. 2006;124:471-84.

107. Deng D, Yao K, Chu W, Li T, Huang R, Yin Y, et al. Impaired translation initiation activation and reduced protein synthesis in weaned piglets fed a low-protein diet. J Nutr Biochem. 2009;20:544-52.

108. Wood JD, Enser M, Fisher AV, Nute GR, Sheard PR, Richardson Rl, et al. Fat deposition, fatty acid composition and meat quality: a review. Meat Sci. 2008;78:343-58

109. Doran O, Moule SK, Teye GA, Whittington FM, Hallett KG, Wood JD. A reduced protein diet induces stearoyl-CoA desaturase protein expression in pig muscle but not in subcutaneous adipose tissue: relationship with intramuscular lipid formation. Brit J Nutr. 2006;95:609-17.

110. Cheng C, Zhang X, Xia M, Liu Z, Wei H, Deng Z, et al. Effect of oregano essential oil and benzoic acid supplementation to a low-protein diet on meat quality, fatty acid composition, and lipid stability of longissimus thoracis muscle in pigs. Lipids Health Dis. 2017;16:164.

111. Xue PC, Ajuwon KM, Adeola O. Phosphorus and nitrogen utilization responses of broiler chickens to dietary crude protein and phosphorus levels. Poult Sci. 2016:95:2615-23.

112. Xue PC, Ragland D, Adeola O. Influence of dietary crude protein and phosphorus on ileal digestion of phosphorus and amino acids in growing pigs. J Anim Sci. 2017;95:2071-9.

113. Jørgensen $\mathrm{H}$, Jakobsen $\mathrm{K}$, Eggum BO. The influence of different protein, fat and mineral levels on the digestibility of fat and fatty acids measured at the terminal ileum and in faeces of growing pigs. Acta Agriculturae Scandinavica A-Animal Sciences. 1992:42:177-84.

114. Adams $\mathrm{KL}$, Jensen $\mathrm{AH}$. Effect of dietary protein and fat levels on the utilization of the fat in sunflower seeds by the young pig. Anim Feed Sci Technol. 1985;13:159-70

115. Noblet J, Fortune H, Shi XS, Dubois S. Prediction of net energy value of feeds for growing pigs. J Anim Sci. 1994;72:344-54.

116. Chen H, Yi X, Zhang G, Lu N, Chu L, Thacker PA, et al. Studies on reducing nitrogen excretion: I. Net energy requirement of finishing pigs maximizing performance and carcass quality fed low crude protein diets supplemented with crystalline amino acids. J Anim Sci Biotechnol. 2011;2:84-93.

117. Le Bellego L, van Milgen J, Dubois S, Noblet J. Energy utilization of lowprotein diets in growing pigs. J Anim Sci. 2001;79:1259-71.

118. Yi X. Study on net energy requirements of grower and finisher pigs fed low crude protein diets. Beijing: PhD Diss. Chin Agric Univ; 2009.

119. Stein HH, Seve B, Fuller MF, Moughan PJ, de Lange CF. Invited review: amino acid bioavailability and digestibility in pig feed ingredients: terminology and application. J Anim Sci. 2007;85:172-80.

120. Boisen S. Ideal dietary amino acid profiles for pigs. Amino acids in animal nutrition; 2003. p. 157-68.

121. Ma W, Zhang S, Zeng X, Liu X, Xie C, Zhang G, et al. The appropriate standardized ileal digestible tryptophan to lysine ratio improves pig performance and regulates hormones and muscular amino acid transporters in late finishing gilts fed low-protein diets. J Anim Sci. 2015;93:1052-60.

122. Liu X, Ma W, Zeng X, Xie C, Thacker PA, Htoo JK, et al. Estimation of the standardized ileal digestible valine to lysine ratio required for 25-to 120kilogram pigs fed low crude protein diets supplemented with crystalline amino acids. J Anim Sci. 2015;93:4761-73.

123. Robbins KR, Saxton AM, Southern LL. Estimation of nutrient requirements using broken-line regression analysis. J Anim Sci. 2006;84(Suppl 13):E155-65. 
124. Zhang G. Study on the optimal tryptophan, thronine, and sulfur amino acids to lysine ratios for growing pigs. Beijing: PhD Diss. Chin Agric Univ; 2011.

125. Xie C. Estimation of the optimum dietary ratio to standardized ileal digestible lysine of threonine, sulfur amino acid and tryptophan for finishing barrows fed reduced protein diet. Beijing: PhD Diss. Chin Agric Univ; 2013.

126. Zhu L. Study on requirements of standardized ileal digestible lysine for finishing pigs fed low protein diets. Beijing: M. S. Thesis. Chin Agric Univ; 2010.

127. Lu N. Study on requirements of standardized ileal digestible lysine for growing pigs fed low crude protein diets. Beijing: M. S. Thesis. Chin Agric Univ; 2010.

128. Ma W. Study on the limiting amino acid pattern for late finishing pigs fed protein reduced diet. Beijing: PhD Diss. Chin Agric Univ; 2015.

129. Liu X. Study on the optimal standardized ileal digestible valine to lysine ratios for growing and finishing pigs fed low crude protein diets and its regulatory effects on feed intake. Beijing: PhD Diss. Chin Agric Univ; 2016

130. Deng D, Huang R, Li T, Wu G, Xie M, Tang Z, et al. Nitrogen balance in barrows fed low-protein diets supplemented with essential amino acids. Livest Sci. 2007;109:220-3.

131. O'Shea CJ, Lynch B, Lynch MB, Callan JJ, O'Doherty JV. Ammonia emissions and dry matter of separated pig manure fractions as affected by crude protein concentration and sugar beet pulp inclusion of finishing pig diets. Agric Ecosyst Environ. 2009;131:154-60

132. Galassi G, Colombini S, Malagutti L, Crovetto GM, Rapetti L. Effects of high fibre and low protein diets on performance, digestibility, nitrogen excretion and ammonia emission in the heavy pig. Anim Feed Sci Technol. 2010;161:140-8.

133. Monteiro A, Bertol TM, de Oliveira P, Dourmad J, Coldebella A, Kessler AM. The impact of feeding growing-finishing pigs with reduced dietary protein levels on performance, carcass traits, meat quality and environmental impacts. Livest Sci. 2017;198:162-9.

134. Portejoie S, Dourmad JY, Martinez J, Lebreton Y. Effect of lowering dietary crude protein on nitrogen excretion, manure composition and ammonia emission from fattening pigs. Livest Prod Sci. 2004;91:45-55.

135. Atakora JKA, Moehn S, Ball RO. Enteric methane produced by finisher pigs is affected by dietary crude protein content of barley grain based, but not by corn based, diets. Anim Feed Sci Technol. 2011;166:412-21.

\section{Ready to submit your research? Choose BMC and benefit from:}

- fast, convenient online submission

- thorough peer review by experienced researchers in your field

- rapid publication on acceptance

- support for research data, including large and complex data types

- gold Open Access which fosters wider collaboration and increased citations

- maximum visibility for your research: over $100 \mathrm{M}$ website views per year

At BMC, research is always in progress.

Learn more biomedcentral.com/submissions 